\title{
Effects of nano thickener deposited film on the behaviour of starvation and replenishment of lubricating greases
}

\author{
Lu HUANG ${ }^{1,2}$, Dan GUO ${ }^{2,}$, Xiang LIU ${ }^{1,2}$, Guoxin XIE ${ }^{2}$, George T Y WAN ${ }^{2}$, Shizhu WEN ${ }^{2}$ \\ ${ }^{1}$ National Institute of Metrology, Beijing 100029, China \\ ${ }^{2}$ State Key Laboratory of Tribology, Tsinghua University, Beijing 100086, China \\ Received: 02 March 2016 / Revised: 06 June 2016 / Accepted: 25 July 2016 \\ (C) The author(s) 2016. This article is published with open access at Springerlink.com
}

\begin{abstract}
The mechanism of grease replenishment in and around a starved point contact was studied in this work. Greases made of different thickeners and same base oil were tested and compared. Disappearing and re-formation of a dynamic grease reservoir during operation revealed that grease bled oil to replenish contact. However, the replenishment process was slow because of the presence of grease fingers along the track and thickener-deposited film inside the track. The contact angles of base oil on the chromium-coated surface and thickener-deposited surfaces were measured. Results proved that the contact angle on the deposited film remarkably increased compared with that on the chromium-coated surface from $25^{\circ}$ to more than $40^{\circ}$. However, the deposited film could be consumed with continuous rolling, and replenishment was then enhanced.
\end{abstract}

Keywords: grease; starvation; thickener; deposited film; replenishment; contact angle

\section{Introduction}

Grease life in a bearing usually refers to its ability to maintain lubrication and protect the tribo-pair from contact with each other. Grease generates a higher film thickness than its base oil under fully flooded conditions [1-3], because of the presence of a thickener. However, in most cases, a bearing functions under the starvation phase [4]. During this phase, most of the grease is pushed aside the rolling track, leaving only a small amount of grease to lubricate contact. Numerous studies on grease starvation have been conducted. Grease has been tested at different operation conditions (at various loads, speeds, temperatures, slide/roll ratios, etc.) [5-8], and results showed that slide/roll and vibration conditions at a relatively high temperature can help replenish contact, whereas high load and speed contribute to more severe starvation. The effect of grease property on its lubrication performance was also studied. Cann et al. [2,9] reported

* Corresponding author: Dan GUO.

E-mail: guodan26@tsinghua.edu.cn that high thickener concentration and base oil viscosity might cause more severe starvation. Huang et al. [10] found that thickener type and the polarity of base oil also play very important roles in central film thickness generation and lubricant reservoir formation during operation.

Venner et al. [11] recently estimated the starved grease film thickness in rolling bearings. The calculated results agreed well with the measured ones within a limited time slot. However, thickener destruction, base oil reflow, and thickener-deposited film in the rolling track also play crucial roles in the long term. Grease maintains long-term lubricity by bleeding base oil into the contact $[12,13]$, and the properties of bled oil were studied by Morales-Espejel et al. [14]. However, detailed studies on the effects of deposited film are rare. Thickeners have been observed to pass through contact [15]. Cann et al. [9] assumed that thickener debris is squeezed out of the contact and then deposited in the rolling track. The properties of deposited film and its influence on lubrication remain unclear, and these properties may change with different grease types. In this study, three kinds of greases made of different 
types of thickeners but the same kind of base oil were tested under starved conditions. Film thickness decay and recovery at different rolling speeds were measured and compared. Lubricant reflow around the contact was observed directly to evaluate the replenishment ability of the different kinds of greases. Surface wettability of both the chromium-coated glass disc and thickener-deposited film was studied to further explain the results.

\section{Experimental}

\subsection{Lubricants}

The lubricants used in this study and their properties are given in Table 1. Three kinds of greases composed of the same base oil but different thickeners were tested and compared. To further explain the replenishment mechanism in starved grease lubrication, base oil was tested alone at the same operation conditions.

\subsection{Film thickness and lubricant reflow}

Starved film thickness was measured on a homemade ball-on-disc test rig [6]. The ball and disc were made of highly polished steel and glass, respectively. The lower side of the disc was coated with chromium. The radius of the ball was $12.7 \mathrm{~mm}$, and the maximum Hertzian contact pressure was approximately $0.7 \mathrm{GPa}$ when loading the ball against the disc. To obtain repeatable results, a thin layer of grease was smeared onto the lower side of the disc, of which the thickness was carefully checked before each test. Temperature was maintained at $25^{\circ} \mathrm{C}$ during the tests. The initial grease layer was the only source of grease supply, and no more grease was added again during a single test. Relative optical interference intensity [10] was then employed to measure the central film thickness of contact under starved conditions at 100, 250, and $500 \mathrm{~mm} / \mathrm{s}$. To analyze the replenishment mechanism, each test was suddenly halted after 100, 200, 300, 400, and 500 revolutions to observe the behavior of mobile lubricant reflowing around the contact driven by capillary pressure. Given that the configuration near the contact was fixed, the reflowing behavior was mainly determined by the mobile lubricant and surface wettability.

\subsection{Contact angle}

A previous study reported [16] that surface wettability plays an important role in lubricant replenishment. To evaluate the influence of the thickener-deposited film on replenishment, the contact angles of base oil on both of the clean chromium-coated disc and thickener-deposited disc were measured and compared. For real solid surfaces, the Young and receding contact angles are experimentally unattainable, so the advancing angle was measured in the present study to evaluate surface wettability $[17,18]$.

Table 1 Properties of the lubricants.

\begin{tabular}{|c|c|c|c|c|}
\hline & LiP8 & UP8 & SiP8 & PAO8 \\
\hline Thickener type & $\begin{array}{l}\text { Lithium (stearate+ } \\
\text { 12-hydroxy stearate) }\end{array}$ & Diurea & $\begin{array}{c}\text { Silica } \\
\text { (nanoparticle) }\end{array}$ & - \\
\hline Base oil type & PAO8 & PAO8 & PAO8 & - \\
\hline $\begin{array}{c}\text { Base oil viscosity } \\
\left(40^{\circ} \mathrm{C} / 100{ }^{\circ} \mathrm{C}\right)\end{array}$ & $46 \mathrm{~mm}^{2} / \mathrm{s} / 8 \mathrm{~mm}^{2} / \mathrm{s}$ & $46 \mathrm{~mm}^{2} / \mathrm{s} / 8 \mathrm{~mm}^{2} / \mathrm{s}$ & $46 \mathrm{~mm}^{2} / \mathrm{s} / 8 \mathrm{~mm}^{2} / \mathrm{s}$ & $46 \mathrm{~mm}^{2} / \mathrm{s} / 8 \mathrm{~mm}^{2} / \mathrm{s}$ \\
\hline Thickener concentration & $12 \%$ & $12 \%$ & $11 \%$ & - \\
\hline Dynamic oil bleeding ratio [19] & $20 \%$ & $17.5 \%$ & $38 \%$ & - \\
\hline Thickener structure (by SEM) & & & 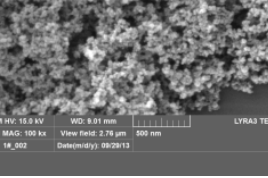 & - \\
\hline
\end{tabular}




\section{Results}

\subsection{Central film thickness}

Figures 1(a)-1(c) show the central film thickness of the three kinds of greases and the corresponding base oil at different rolling speeds under starved conditions. To compare the film formation and replenishment ability of base oil and grease, the initial lubricant supply was ensured the same by checking the size of stationary lubricant reservoir around the contact before the test. For both grease and oil, the initial lubricant reservoir was about $1,200 \mu \mathrm{m}$ in radius.

Figure 1(a) shows that the central film thickness of PAO8 was almost constant throughout the test at $100 \mathrm{~mm} / \mathrm{s}$, whereas that of LiP8 and SiP8 decreased initially and then recovered to some degree after 70 and 225 revolutions, respectively. The central film thickness of UP8 decreased to around $90 \mathrm{~nm}$ after 10 revolutions and remained constant for a while; after about 100 revolutions, it decreased again to around
$25 \mathrm{~nm}$ and remained constant for a certain period; after 250 revolutions, it also recovered. The unique behavior of UP8 was due to its good adhesive property to metal surface. Considering that the initial grease/oil reservoir was the same, the results indicated that base oil replenished the contact very well during the operation, whereas most of the grease was pushed away and hardly reflowed back to the contact. SiP8 exhibited the best replenishment ability, followed by LiP8 and UP8. Bled oil reflowing back to replenish the contact was of vital importance to a starved contact. The speed and amount of bled oil to reflow were two key factors to evaluate the effect of replenishment.

Figures 1(b) and 1(c) show the central film thickness of the four lubricants at 250 and $500 \mathrm{~mm} / \mathrm{s}$, respectively. Similar trends could be found from the two figures. The thickness of base oil film remained constant, whereas that of grease film decreased. Recovery of the film thickness appeared later when the rolling speed increased. The starved film thickness of SiP8 began to recover after 75 revolutions at $100 \mathrm{~mm} / \mathrm{s}$, but
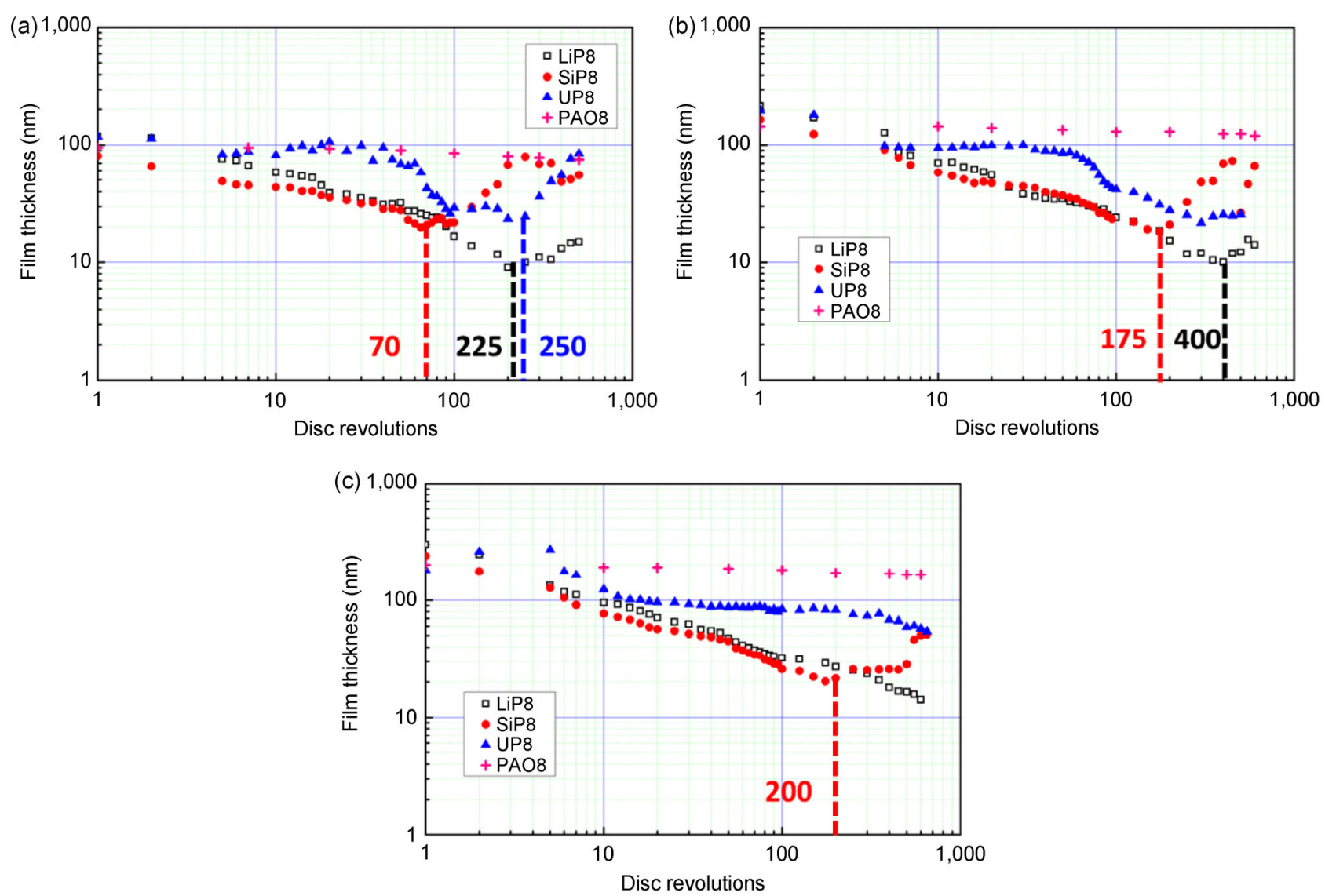

Fig. 1 Grease and base oil film thickness at (a) $100 \mathrm{~mm} / \mathrm{s}$, (b) $250 \mathrm{~mm} / \mathrm{s}$, and (c) $500 \mathrm{~mm} / \mathrm{s}$. 
this value increased to 175 at $250 \mathrm{~mm} / \mathrm{s}$. LiP8 showed no film thickness recovery at $250 \mathrm{~mm} / \mathrm{s}$ until after 400 revolutions. Urea grease showed no recovery at $250 \mathrm{~mm} / \mathrm{s}$. At $500 \mathrm{~mm} / \mathrm{s}$, only SiP8 showed film thickness recovery within the test limit.

The film thickness platform of UP8 indicated that this kind of grease possessed very strong adhesion ability rather than fluidity. With the same base oil and thickener concentration, UP8 always generated higher film thickness than the other two kinds of greases if film thickness recovery was not considered.

\subsection{Lubricant reflow}

Film thickness recovery could be regarded as an indirect evidence of lubricant replenishment. In this section, the behavior of both dynamic and static lubricant reservoirs was observed and analyzed to further evaluate lubricant replenishment ability.

Dynamic reservoir in this work was defined as the lubricant reservoir around the contact during operation, whereas static reservoir was defined as the lubricant reservoir when the test was halted. Figure 2 shows the dynamic reservoir of PAO8, LiP8, SiP8, and UP8 during the tests.
Figure 2 illustrates that oil reservoir stabilized immediately after the test started. This finding corresponded with the film thickness results shown in Fig. 1. The film thickness of pure PAO8 quickly became stable after the test started. Unlike oil, grease reservoir was almost lost during the first five revolutions because of its poor mobility. Most of the grease was pushed outside the contact and hardly reflowed back. However, as proposed in our earlier work [19], a reformed lubricant reservoir consisting mostly of base oil and a small fraction of thickener debris appeared under the effect of shearing. The mobile lubricant was called bled oil, which meant that it was bled out of grease. Although the grease structure could be sheared broken and release oil to re-build the lubricant reservoir, it presented a limitation. As most of the grease was already pushed away in the first several revolutions, only a small amount of grease adhered along the rolling track and appeared like fingers. The re-formed reservoir was mainly from these grease fingers and the main cause of grease replenishment under starved conditions. In real bearing applications, the cage effect cannot be neglected because it may force grease that has been pushed aside to replenish

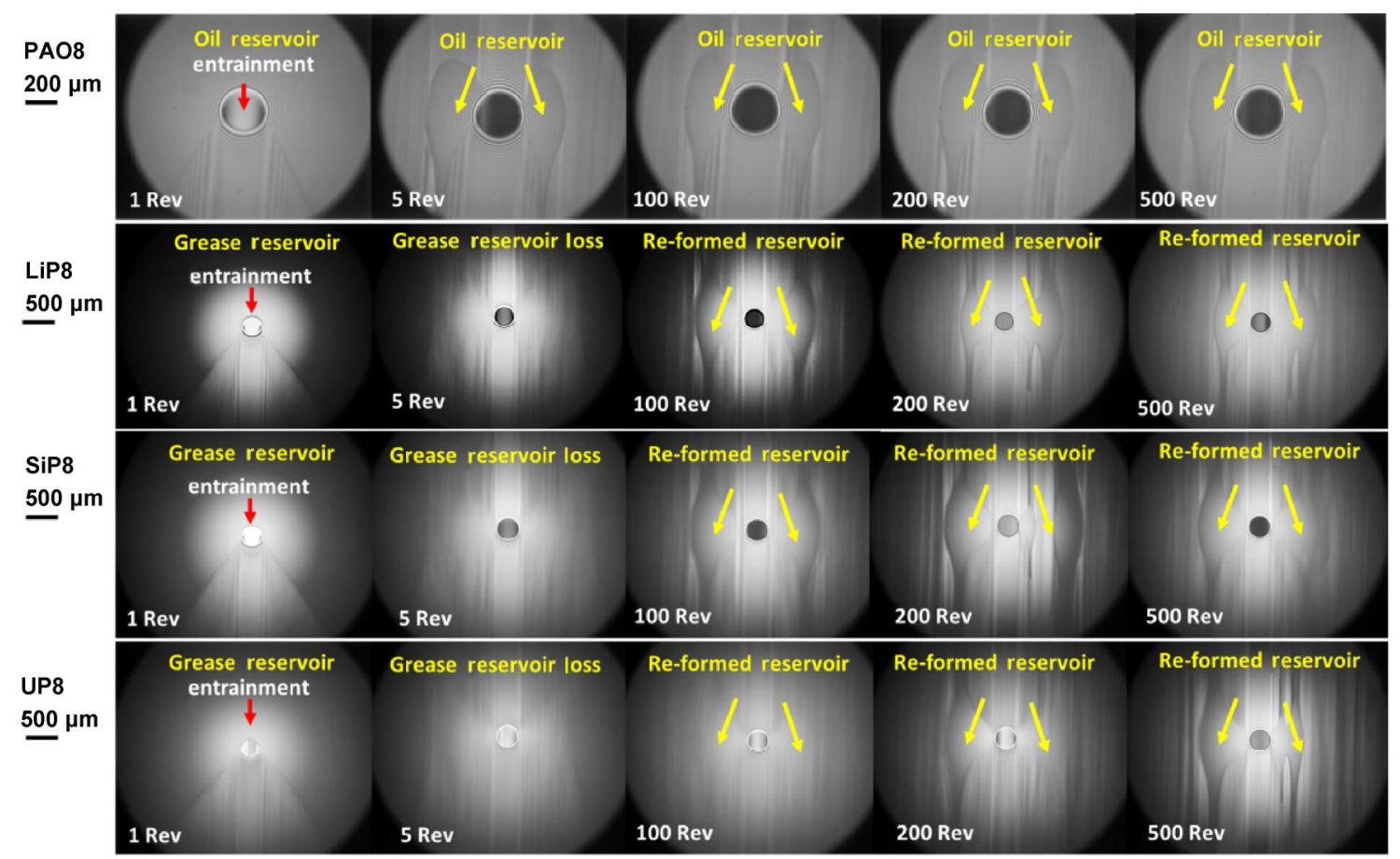

Fig. 2 Dynamic reservoir formed by different lubricants. All these photos were taken at $250 \mathrm{~mm} / \mathrm{s}$ after rolling for 1, 5, 100, 200, and 500 revolutions, respectively. 
the contact. However, this effect was not considered in the present study because we mainly focused on grease properties.

For the three kinds of greases, the re-formed reservoirs stabilized after operating for about 100 revolutions. However, the film thicknesses still decreased, which was very different from the behavior of oil. The recovery of central film thickness was observed long after the lubricant reservoir stabilized, and it was also different from grease. To further understand the replenishment mechanism, the test rig was suddenly halted during operation to observe the behavior of lubricant reflowing back to the track at static condition.

Figure 3 shows the evolution of base oil reservoir when the test was halted after 100 revolutions. At this moment, oil was driven to reflow back to the track through the combined effects of capillary pressure $P_{\mathrm{c}}$ and disjoining pressure $P_{\mathrm{d}}$ :

$$
P=P_{\mathrm{c}}-P_{\mathrm{d}}
$$

$P_{\mathrm{c}}$ and $P_{\mathrm{d}}$ are defined respectively as [20, 21]:

$$
\begin{gathered}
P_{\mathrm{c}}=\gamma_{\mathrm{LV}} K \\
P_{\mathrm{d}}=-A /(6 \pi \delta)^{3}
\end{gathered}
$$

where $\gamma_{\mathrm{LV}}$ is the surface tension of the liquid and $K$ is the curvature of the film in Eq. (2); $A$ is the Hamaker constant $\left(A=24 \pi D_{\mathrm{o}}^{2} \gamma_{\mathrm{LV}}\right)$ and $\delta$ is the film thickness in Eq. (3). Inlet distance $D$ versus time was measured as a criterion to describe the reflowing speed of oil. The results showed that the inlet oil reflowed back very quickly after the test rig was stopped. The inlet distance grew from $0 \mu \mathrm{m}$ to $230 \mu \mathrm{m}$ in only $1 \mathrm{~s}$.

The results presented by Lubrecht et al. [22] proved that the influence of disjoining pressure $P_{\mathrm{d}}$ on oil reflowing was so small and localized that it did not play a major role. Thus, only the influence of $P_{\mathrm{c}}$ is discussed in this paper. The cross-section diagrams in Fig. 3 clearly demonstrated that oil might reflow back to the contact from two directions: the moving direction and the direction perpendicular to it. Section A-A shows the reflow from two butterfly wing-shaped oil reservoirs. The radius of the oil-air meniscus closer to the track was smaller than that away from the track, so the resultant capillary pressure could drive oil to reflow toward the track. Section B-B shows the inlet distance growing in front of the starved contact. When the test stopped, oil trapped inside the contact was squeezed out by the contact pressure $P$ and reflowed to the track. Of course, this effect would not occur during the operation. Given that oil spreads on
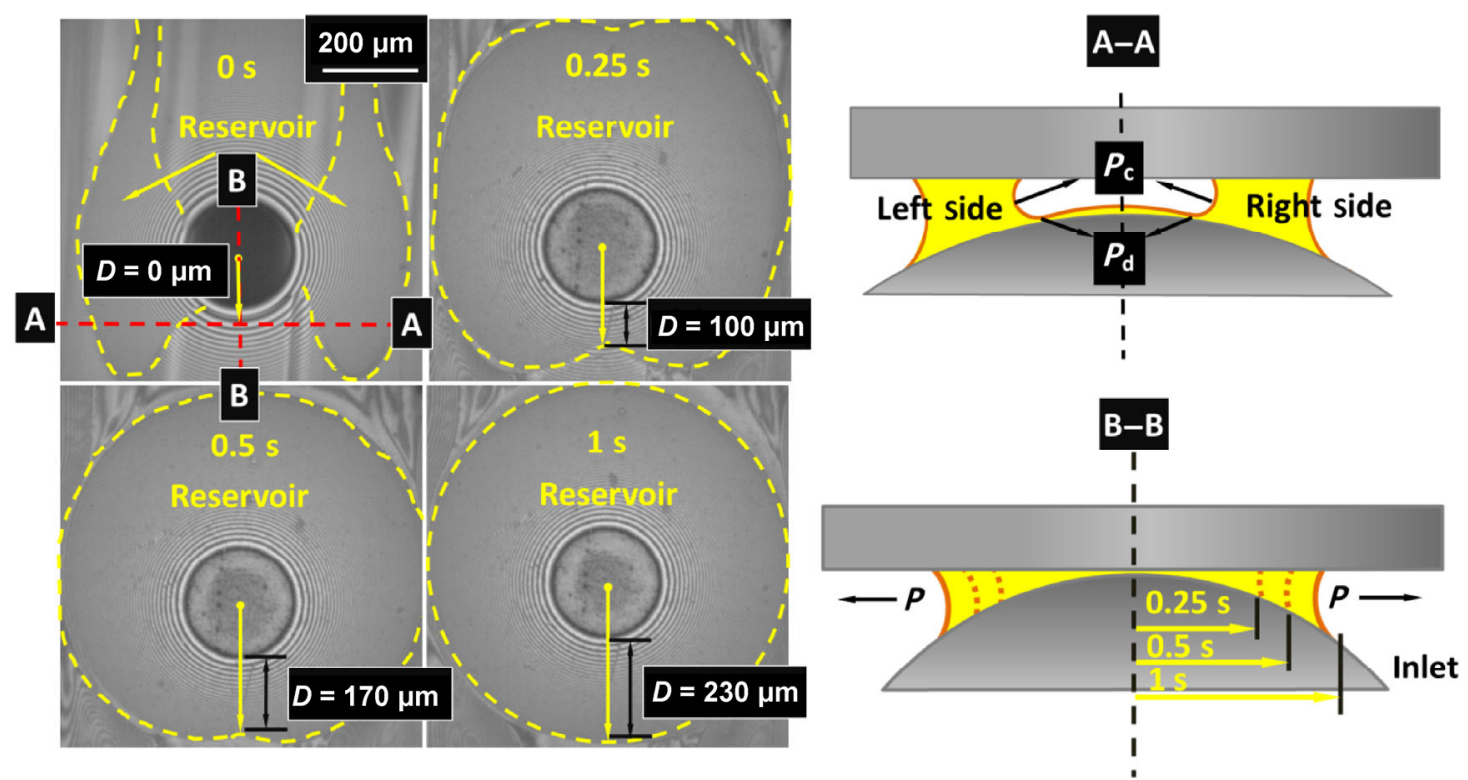

Fig. 3 Oil reflowed back to the contact when the test was suddenly halted. Photos on the left show the reflowing process after the test rig was halted; diagrams on the right show that oil was driven to reflow back to the track by $P_{\mathrm{c}}, P_{\mathrm{d}}$, and $P$ from two dimensions. $D$ represents the inlet distance, which is the distance between the meniscus of lubricant reservoir and Hertzian contact in the inlet direction. 
a metal surface, the meniscus curvature $K$ should be very large so that the reflowing speed is fast. The final profile of the oil reservoir was round, because the geometry and surface property around the contact was isotropic.

Figure 4 shows the bled oil of grease reflowing back to the contact when the test was suddenly halted after 100 revolutions. Unlike base oil, the grease reservoir retained its shape long after the test was halted, whereas the mobile lubricant reflowed back around the contact. The reflowing process of grease was much slower than that of base oil. Table 2 shows a comparison between

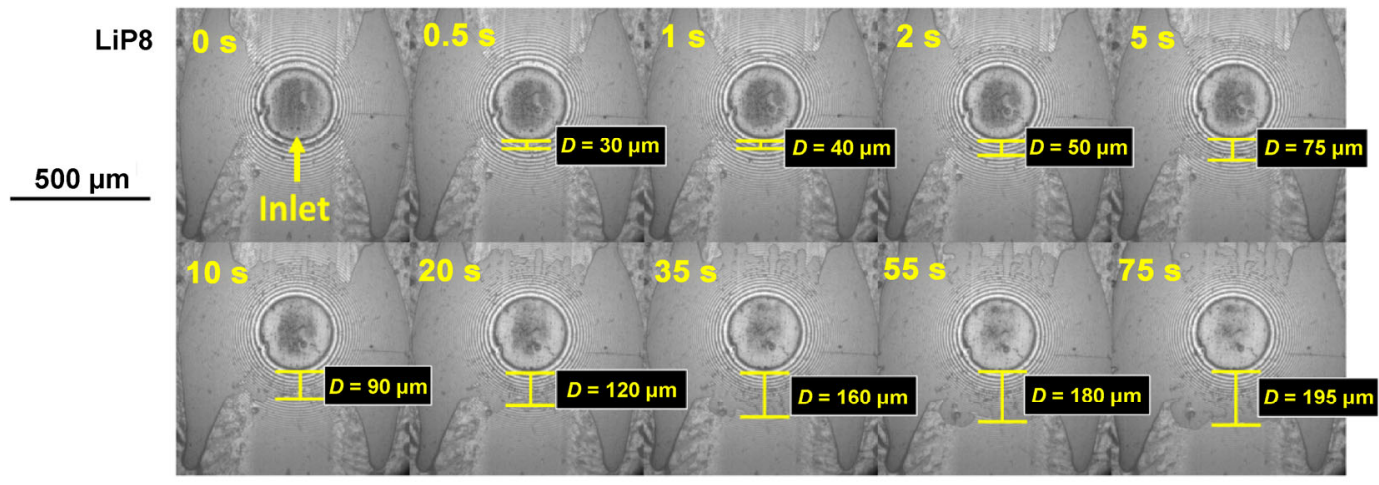

SiP8

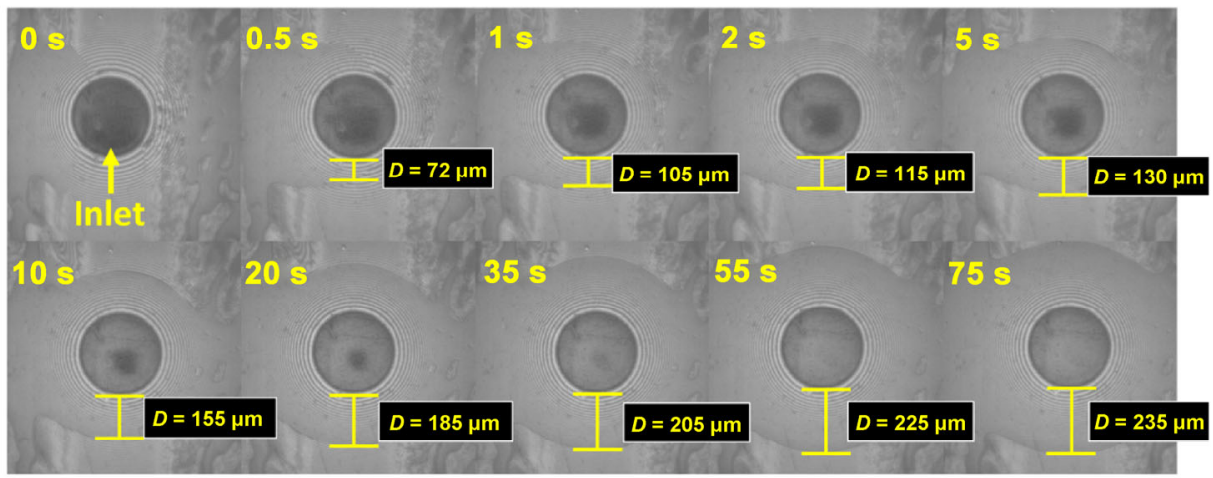

UP8

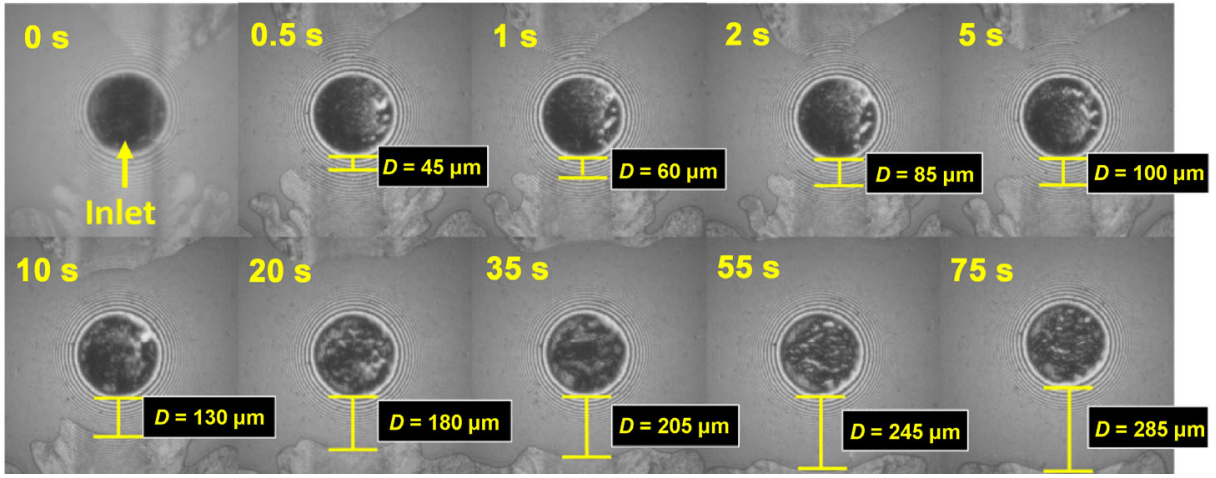

Fig. 4 Reflowing behavior of grease when the test was suddenly halted (test speed: $250 \mathrm{~mm} / \mathrm{s}$ ).

Table 2 Oil versus grease in the reflowing behavior around a point contact.

\begin{tabular}{|c|c|c|c|c|c|c|c|c|c|c|}
\hline \multirow[b]{2}{*}{ Item } & \multicolumn{10}{|c|}{ Evolution of inlet distance $D$ with time $(\mu \mathrm{m})$} \\
\hline & $0.25 \mathrm{~s}$ & $0.5 \mathrm{~s}$ & $1 \mathrm{~s}$ & $2 \mathrm{~s}$ & $5 \mathrm{~s}$ & $10 \mathrm{~s}$ & $20 \mathrm{~s}$ & $35 \mathrm{~s}$ & $55 \mathrm{~s}$ & $75 \mathrm{~s}$ \\
\hline PAO8 & 100 & 170 & 230 & 260 & - & - & - & - & - & - \\
\hline LiP8 & 15 & 30 & 40 & 50 & 75 & 90 & 120 & 160 & 180 & 195 \\
\hline SiP8 & 45 & 72 & 105 & 115 & 130 & 155 & 185 & 205 & 225 & 235 \\
\hline UP8 & 30 & 45 & 60 & 85 & 100 & 130 & 180 & 205 & 245 & 285 \\
\hline
\end{tabular}


oil and grease.

Three main differences were evident from Figs. 3 and 4 and Table 2:

- Reflow of base oil was much faster than that of grease.

- The grease reservoir retained its shape in the reflowing process, whereas the oil reservoir quickly shrank toward the contact and finally became completely round.

- In the case of LiP8, the boundary of reflowed lubricant in the track was so coarse as if the track surface was contaminated, whereas that for SiP8 and UP8 was much smoother and similar to that of oil.

A previous study reported [23] that the reflowed mobile lubricant is mainly base oil bleeding out of grease because of shearing and heating. The different reflowing behaviors of grease and oil were expected to be due to the presence of thickener rather than the reflowed oil. To further understand the mechanism of grease replenishment, thickener deposition and its influence on the oil contact angle were studied.

\subsection{Thickener deposition and contact angle}

To evaluate the presence of thickener-deposited film and its effects on grease replenishment, the rolling track on the disc was detected by using atomic force microscopy (AFM; Veeco, USA) after each test. The contact angles of PAO8 both on the chromium-coated disc and thickener-deposited disc were measured and compared.

Figure 5 shows the track lubricated with each grease sample after rolling for 100 revolutions. The upper photos were taken by the high-resolution CCD of $\mathrm{AFM}$, and the lower photos are the scanned results.

Different patterns of thickener-deposited film were clearly observed in these rolling tracks. Detailed scanning revealed small and granular debris from the deposited films of LiP8 and SiP8; however, no further information on UP8 could be found. This result indicated that the deposited film of UP8 contained a high base oil content or was so sticky such that the AFM tip was contaminated during the scanning process. By contrast, the deposited film of LiP8 and SiP8 contained a high thickener content and was less sticky.

Results from Fig. 5 proved the presence of the thickener-deposited film in the rolling track. To further analyze the effect of the thickener-deposited film on the speed of grease replenishment, the contact angles of base oil both on the chromium-coated disc and thickener-deposited disc were measured. Thickenerdeposited surfaces were acquired as follows:

- About 1-2 g of grease sample was dissolved into a tube of cyclohexane.

- The mixture was then placed into a centrifuge for

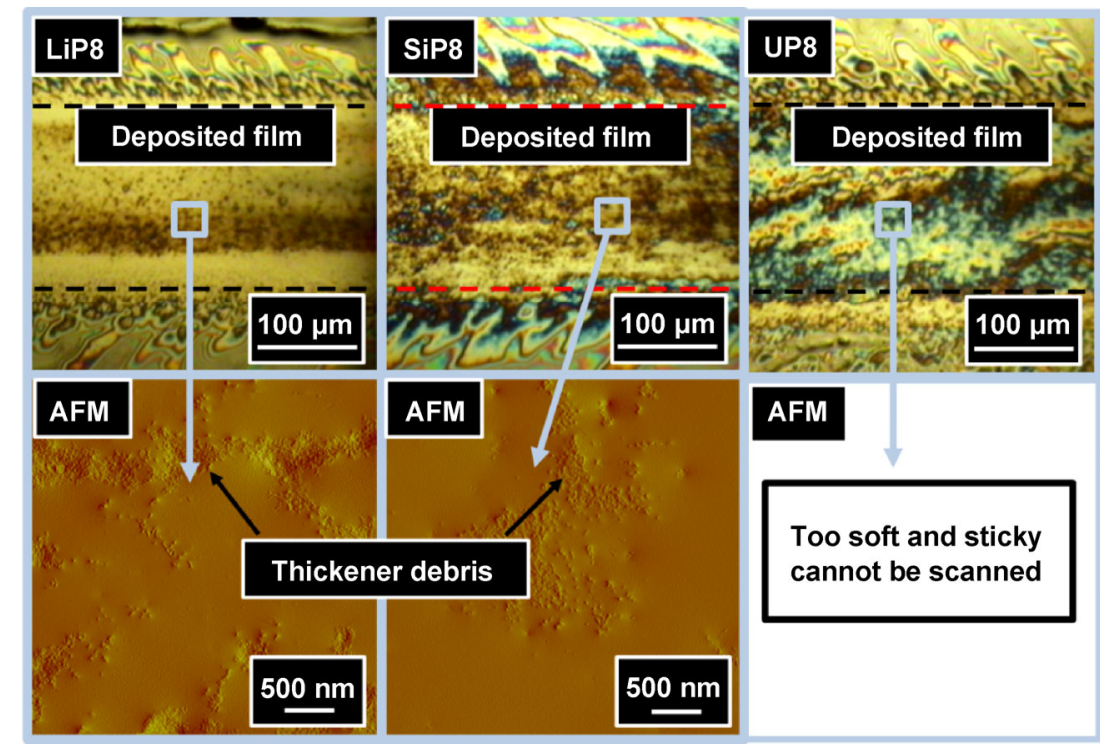

Fig. 5 Thickener-deposited film in the rolling track. 
$15 \mathrm{~min}$ at a rotational speed of $8,000 \mathrm{r} / \mathrm{min}$, in which base oil was separated from the thickener.

- The thickener was removed and smeared evenly onto the chromium-coated disc, after which the disc was rolled for 100 revolutions to obtain the thickener-deposited track.

- Redundant thickener along the rolling track was carefully removed using a small scoop, after which the disc was dried in an oven for $5-10 \mathrm{~min}$ at $80{ }^{\circ} \mathrm{C}$ to allow cyclohexane to fully evaporate.

Figure 6 shows the contact angle of PAO8 both on the chromium-coated disc and thickener-deposited track. The upper figures illustrate the dynamic contact angle, whereas the lower figures display the static contact angle. The dynamic contact angle of PAO8 on the clean chromium-coated surface was about $25^{\circ}$, and the droplet on this surface spread very well. However, the wettability of oil on the thickener-deposited surfaces of all the three tested greases decreased. The dynamic contact angle on the thickener-deposited surface of LiP8 and UP8 increased by more than $100 \%$ compared with that on the chromium-coated surface. In the case of SiP8, the dynamic contact angle increased by about $60 \%$.

\section{Discussion}

\subsection{Mechanism of grease starvation and replenishment}

When a point contact was purely lubricated with base oil, the local replenishment around the contact was very fast. However, under starved grease lubrication, the replenishment mechanism became more complex because of the presence of a thickener. In the ball-on-disc test, most of the grease was pushed outside the contact, leaving only a small amount of grease shaped like fingers or branches attached along the rolling track. The finger-shaped grease became the only source of grease supply during the operation. In real applications, such as in a ball bearing, the cage effect cannot be neglected. The bearing finally entered the starvation phase, but the fully flooded phase in the beginning could last longer than in a ball-on-disc test without a cage.

With the effect of successive shearing, the thickener structure inside these grease fingers was broken, so the base oil inside bled out to replenish the starved contact caused by the local capillary pressure. However, this replenishment process was much slower than that of oil. On the one hand, grease fingers geometrically functioned like barriers that prevented bled oil from reflowing toward the track. This action was proven by the results shown in Fig. 4 . The profiles of the LiP8 reservoir slightly changed during the reflowing process, whereas the reflowed lubricant increased the inlet distance. In the case of oil, the lubricant reservoir along the rolling track shrank toward each other very quickly after the test was halted. On the other hand, thickener debris was deposited in the rolling track, leading to an increase in the oil contact angle on the surface of the rolling track, so that the capillary pressure became smaller. This phenomenon made grease replenishment even more difficult.

The oil bleeding ratios of LiP8 and UP8 were much lower than that of SiP8. Therefore, the available amount of bled oil to replenish the track was very small in the case of LiP8 and UP8. The wettability of the track surface was affected by the thickener-deposited film, so the replenishing speeds of LiP8 and UP8 were
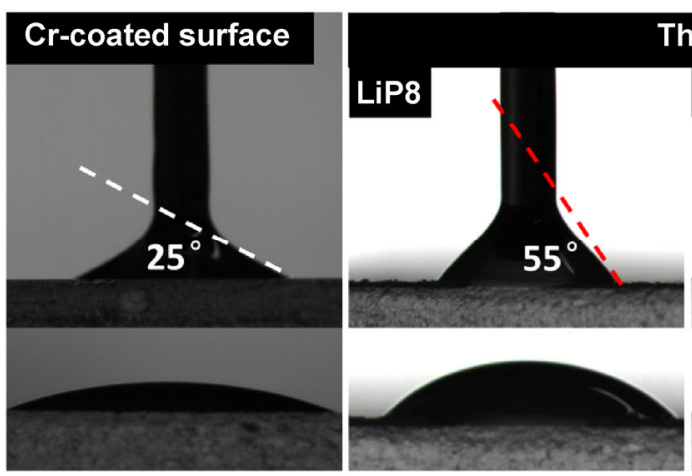

Thickener-deposited surface

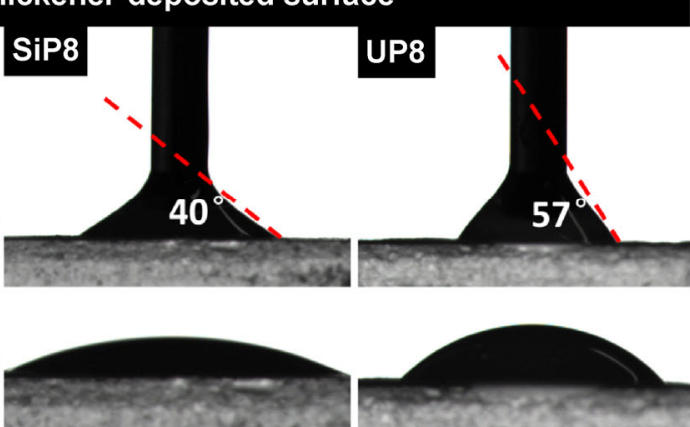

Fig. 6 Contact angle of PAO8 both on the chromium-coated surface and thickener-deposited surface. 
much lower than that of SiP8, and the final size of their lubricant reservoirs was also smaller. SiP8 bled a great deal of oil, and its deposited film showed better wettability than that of LiP8 and UP8 such that both of its replenishing speed and amount were considerable.

Although UP8 had the lowest oil bleeding ratio, the final size of its lubricant reservoir was still larger than that of LiP8. This finding was mainly because UP8 showed very good adhesive property to the chromium surface, which indicated the presence of more grease fingers attached along the rolling track. The connection and combination with nearby grease fingers might be the main reason for the large final reservoir size.

\subsection{Influence of rolling time}

Another complex problem was that the thickness of the starved grease film sometimes recovered to some degree after a period of operation. This observation meant that the replenishing behavior changed with the rolling time. Two possible explanations were offered for this change: one was that more oil bled out with successive shearing; the other was that the effect of grease finger and deposited film became less significant.

At an operating speed of $250 \mathrm{~mm} / \mathrm{s}$, the re-formed lubricant reservoir of SiP8 became stable after 100 revolutions, whereas film thickness recovered after 175 revolutions; the re-formed lubricant reservoir of LiP8 became stable after 200 revolutions, whereas film thickness recovered after 400 revolutions; the re-formed lubricant reservoir of UP8 became stable after 200 revolutions, whereas no film thickness recovery was observed (Figs. 1 and 2). The stability of the lubricant reservoir indicated that the amount of available bled oil no longer changed. Therefore, film thickness recovery was not due to the increase in bled oil but to the change in surface condition.

With the effect of shearing, the thickener-deposited film was consumed. This phenomenon was considered the main reason contributing to replenishment. Figure 7 shows the track condition when the ball and disc rolled for 350 revolutions. Compared with the results shown in Fig. 5, the thickener-deposited film was almost gone. All the three tracks could no longer be scanned by using AFM tips, as the track surface became more viscous and contained more mobile oil than that after rolling for 100 revolutions. When most of the deposited film was consumed during operation, the chromium surface was exposed, which contributed to bled oil reflowing back to the track.

Figure 8 shows a comparison of reflowing speed when the test was halted after 100 and 350 revolutions. Without the weakening of the thickener-deposited film, bled oil reflowed much faster after 350 revolutions than after 100 revolutions.

\subsection{Base oil versus bled oil}

Base oil was used in evaluating the surface wettability of the thickener-deposited track because the amount of bled oil during the operation was too miniscule to be collected. In real applications, bled oil may also contain a high thickener content, which could increase the viscosity of base oil. Replenishment was also affected when the viscosity of reflowed oil increased. Short-chain oil molecules bled out, whereas longchain oil molecules became entangled with thickener fibers so that the viscosity of bled oil decreased.

However, the improvement of replenishment after 100-200 revolutions or more has already, to some degree, proven that the thickener-deposited film was
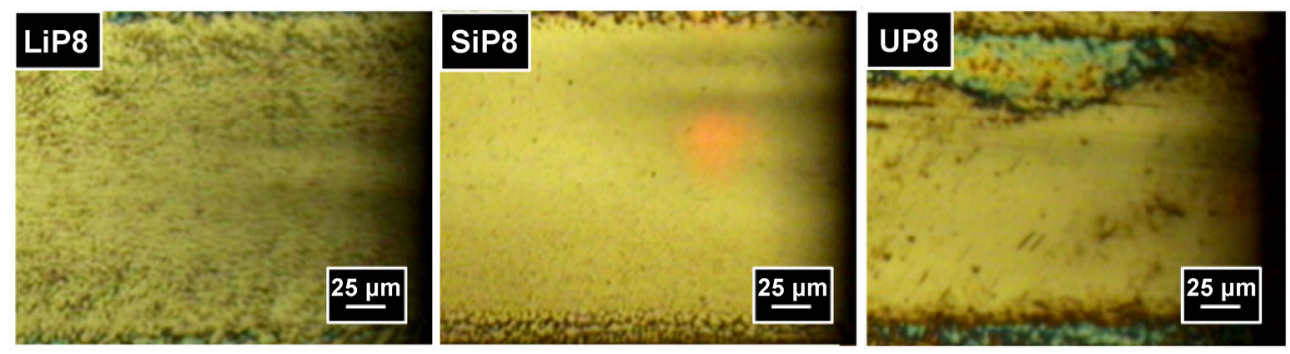

Fig. 7 Track condition after rolling for 350 revolutions. 


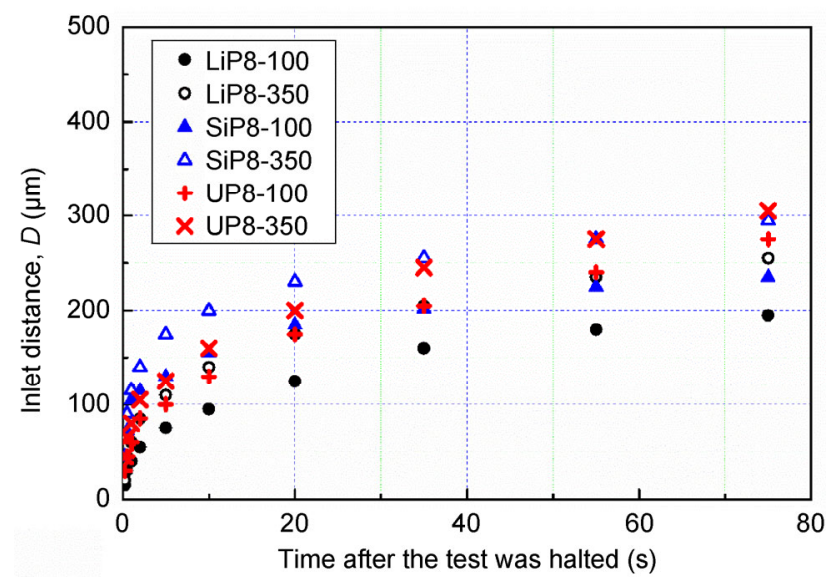

Fig. 8 Evolution of inlet distance $D$ with time after the test was halted.

the main factor that influenced grease replenishment rather than bled oil property. Future work will focus on evaluating bled oil property after real applications.

\section{Conclusions}

In this work, the effect of thickener on the grease replenishment mechanism was discussed. During the operation, most of the bulk grease was pushed outside the contact, and grease fingers along the rolling track were the main source of grease supply under starved lubrication conditions. These fingers could bleed base oil out of the thickener structure to replenish contact after a period of operation. However, replenishment was so slow because of the combined effect of grease fingers and the thickener-deposited film in the rolling track. Grease fingers might function as a natural barrier to prevent bled oil from reflowing back to the track, whereas the thickener-deposited film increased the contact angle of oil on the track surface. After a long period of rolling, grease fingers became softer and the thickener-deposited film was consumed such that replenishment was enhanced. Questions remain on whether the thickener-deposited film protects the metal surface, as well as the differences between base oil and bled oil.

\section{Acknowledgement}

This research is supported by the National Natural Science Foundation of China (Nos. 51375255 and
51321092). The authors also would like to thank Shenzhen Hecheng Lubricant Co. for supplying the special lab-made grease samples.

Open Access: The articles published in this journal are distributed under the terms of the Creative Commons Attribution 4.0 International License (http:// creativecommons.org/licenses/by/4.0/), which permits unrestricted use, distribution, and reproduction in any medium, provided you give appropriate credit to the original author(s) and the source, provide a link to the Creative Commons license, and indicate if changes were made.

\section{References}

[1] Åström H, Isaksson O, Höglund E. Video recordings of an EHL point contact lubricated with grease. Tribol Int 24: 179-184 (1991)

[2] Cann P M. Starved grease lubrication of rolling contacts. Tribol Trans 42: 867-973 (1999)

[3] Kaneta M, Ogata T, Takubo Y, Naka M. Effects of thickener structure on grease elastohydrodynamic lubricant films. Proc IMechE Part J: J Engr Tribol 214: 327-336 (2000)

[4] Lugt P M. Grease Lubrication in Rolling Bearings. John Wiley and Sons, Ltd, 2013.

[5] Nagata Y, Kalogiannis K, Glovnea R. Track replenishment by lateral vibrations in grease-lubricated EHD contacts. Tribol Trans 55: 91-98 (2012)

[6] Huang L, Guo D, Wen S Z, Wan G T Y. Effects of slide/ roll ratio on the behaviours of grease reservoir and film thickness of point contact. Tribol Lett 54: 263-271 (2014)

[7] Li G, Zhang C, Luo J, Liu S, Xie G, Lu X. Film-forming characteristics of grease in point contact under swaying motions. Tribol Lett 35: 57-65 (2009)

[8] Cann P M, Lubrecht A A. Bearing performance limits with grease lubrication: the interaction of bearing design, operating conditions and grease properties. J Phys D: Appl Phys 40: 5446-5451 (2007)

[9] Cann P M, Williamson B P, Coy R C, Spikes H A. The behaviour of greases in elastohydrodynamic contacts. $J$ Phys D: Appl Phys 25: 124-132 (1992)

[10] Huang L, Guo D, Wen S Z. Starvation and reflow of point contact lubricated with greases of different chemical formulation. Tribol Lett 55: 483-492 (2014)

[11] Venner C H, Van Zolen M T, Lugt P M. Thin layer flow and film decay modeling for grease lubricated rolling bearings Tribol Int 47: 175-187 (2012) 
[12] Naka M, Yamazaki M, Yokouchi A, Yamamoto Y. Antiseizure performance of lubricating greases in various types of rolling bearings. In Proc Int Tribol Conf, Nagasaki, Japan, 2000: 1407.

[13] Cann P M. Starvation and reflow in a grease-lubricated elastohydrodynamic contact. Tribol Trans 39: 698-704 (1996)

[14] Morales-Espejel G E, Lugt P M, Pasaribu H R, Cen H. Film thickness in grease lubricated slow rotating rolling bearings. Tribol Int 74: 7-19 (2014)

[15] Eriksson P, Wikström V, Larsson R. Grease passing through an elastohydrodynamic contact under pure rolling conditions. Proc IMechE Part J: J Eng Tribol 214: 309-316 (2000)

[16] Cann P M, Damiens B, Lubrecht A A. The transition between fully flooded and starved regimes in EHL. Tribol Int 37: 859-864 (2004)

[17] Bormashenko E. Wetting of real solid surfaces: New glance on well-known problems. Colloid Polym Sci 291: 339-342 (2013)

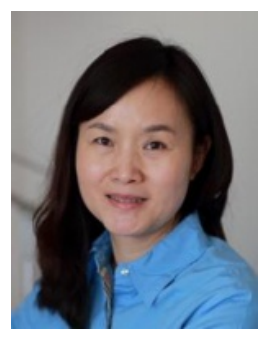

Dan GUO. She received her Ph.D. degree in 1999 from Department of Solid Mechanics, Tsinghua University, Beijing, China. She is now working as an associate professor in the State Key Lab of Tribology, Tsinghua

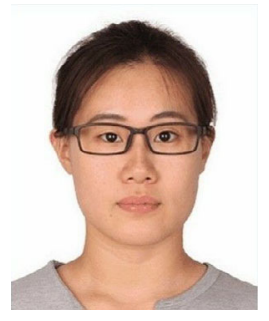

Lu HUANG. She received her Ph.D. degree in 2016 from State Key Lab of Tribology, Tsinghua University, Beijing, China. She studied the
[18] Liu X, Guo D, Liu S, Xie G, Luo J. Interfacial dynamics and adhesion behaviors of water and oil droplets in confined geometry. Langmuir 26: 7695-7702 (2014)

[19] Huang L, Guo D, Wen S Z. Film thickness decay and replenishment in point contact lubricated with different greases: A study into oil bleeding and the evolution of lubricant reservoir. Tribol Int 93: 620-627 (2016)

[20] Liu X, Guo D, Xie G, Liu S,d Luo J. "Boiling" in the water evaporating meniscus induced by Marangoni flow. Appl Phys Lett 101: 211602 (2012)

[21] Maroo S C, Chung J N. Heat transfer characteristics and pressure variation in a nanoscale evaporating meniscus. Int J Heat Mass Transfer 53: 3335-3345 (2010)

[22] Jacod B, Pubilier F, Cann P M, Lubrecht A A. An analysis of track replenishment mechanisms in the starved regime Tribol Ser 99: 483-492 (1999)

[23] Hurley S, Cann P M. IR spectroscopic analysis of grease lubricant films in rolling contacts. Tribol Ser 36: 589-600 (1999)

University, Beijing, China. Her researches are about the mechanical properties of nano-particles and interaction between the nano-particles and the surface, lubrication and failure mechanism under rigorous conditions, and movement behavior of confined-microfluidic.

mechanism of grease lubrication during Ph.D. period. Now she is a post doctor in National Institute of Metrology, Beijing, China. Her research area mainly focuses on the methods of nano-measurement. 